\title{
THE ECONOMIC CRISIS AND THE ROLE OF EXTERNAL AUDIT: THE CASE OF GREECE
}

\author{
Author(s) / Auteur(s): \\ Victoria A. ZGOUVA \\ Auditor in the Court of Audit; CSAP Post graduate student \\ Court of Audit of the Hellenic Republic; University of Piraeus, Department of Informatics \\ zgouva.vicky@gmail.com
}

\author{
Dimitrios S.VARSOS \\ Management system consultant; CSAP Professional \\ University of Piraeus, Department of Informatics; Hellenic Society for Systemic Studies (HSSS); \\ MSI Hellas Consulting Group \\ dvarsos@msi.gr
}

Nikitas A. ASSIMAKOPOULOS

Professor

University of Piraeus, Department of Informatics; Hellenic Society for Systemic Studies (HSSS); assinik@unipi.gr

\begin{abstract}
Résumé:
The global financial crisis of 2008 has been rivaled only by the Great Depression of the 1930s. The breadth and duration of this crisis had an adverse impact on every national economy, reflecting the systemic interdependence of an interconnected economic ecosystem, and the strengths and weaknesses of individual countries, regions, and monetary policies. The economic crises was particularly disparaging to the Greek state, which has a long history of excessive public spending, massive tax evasion, wage growth not supported by proportional productivity, and unsustainable debt levels. The health of the economy was further eroded as a result of a lack of confidence that was driven by questionable accounting practices and the misreporting of economic performance indicators by successive governments. The Court of Audit of the Hellenic Republic ${ }^{1}$ operates as the independent external auditor for the Greek state. Its effective and efficient operation within its mandated boundaries will be instrumental in the nation's economic recovery and a key preventing measure to arrest financial mismanagement in the future. This work will describe the context in which the CoA carries out its activities, and will explore the means through which the organization can apply a systems approach to its structure, function, and management paradigm for the purpose of reinforcing its strategic, operational, and tactical capacity.
\end{abstract}

${ }^{1}$ The Court of Audit (CoA) of the Hellenic Republic is known to the international community as the Hellenic Court of Audit (HCA).

\section{Keywords / Mots-clés:}

Systems approach, independent external audits, international standards, quality management system

\section{INTRODUCTION}

The global financial crisis of 2008 is without precedent in post-war economic history. It resulted in a severe debt crisis in Europe and devastating consequences for the Greek economy that almost toppled the Greek state. The Court of Audit of the Hellenic Republic (CoA), as a member of the International Organization of the Supreme Audit Institution (INTOSAI), is the independent external auditor for the Greek state, and responsible for the oversight of the country's sound Public Financial Management (PFM). The external audits that are carried out by the CoA (in accordance with the International Auditing Standards) aim to identify weaknesses and gaps in the internal control system of the public sector entities, and to hold them accountable for fraud, corruption, and misuse of public funds. The 
endogenous and exogenous causes of the economic crisis reduced public confidence and increased the financial instability in the Greek state. Moreover, the complexity of the Greek financial system calls for specific systemic interventions in the audit systems, practices, and procedures of the CoA. Through the adoption and implementation of new audit methodologies, the systemic risk associated with state spending can be reduced, and the internal control system of the public sector can be improved. Contemporary financial and compliance audit models, tailor-made risk-audit methodologies, alongside the traditional ex-ante and ex-post audits develop a conceptual framework through which the weaknesses of the internal control system of public entities can be transformed into opportunities, thus achieving a higher level of organizational effectiveness and efficiency. This work will attempt to illustrate the means, methods, and benefits of applying a systems approach to the CoA's operations, which together with systems thinking tools and standardized international standards and guidelines will reinforcing the organization's key and enabling processes that relate to its auditing function, thus enabling the CoA overall effectively and capacity to meet its constitutional mandate and its stakeholder's needs and expectations.

\section{THE GREEK DEBT CRISIS: A BRIEF HISTORY}

The Greek government-debt crisis (also known as the Greek Depression) refers to the sovereign debt crisis of the Greek state that started in late 2009. The crisis was a direct result of the structural deficiencies of the Greek economy and the loss of confidence that was a result of questionable accounting practices and misreporting of the Greek economy's economic performance by successive governments (Wikipedia, 2018). The true origins of the causes of the economic crisis can be traced back to the country's premature entry in the Eurozone in the beginning of 2001. The country's first attempt to join the Eurozone was unsuccessful as a result of its inability to meet the 1992 Maastricht Treaty's economic requirements. In 2001, Greece became the 12th member of the Eurozone without fully complying with the five criteria of the EU Stability and Growth Pact, which included low inflation, a budget deficit below 3\% of GDP, and government debt levels below $60 \%$ of GDP. In fact, in 2001, the Greek budget deficit was well in excess of 3\% of GDP and government's debt in excess of $100 \%$ of GDP. Moreover, unsustainable debt levels, excessive public spending, increasing credit expansion, massive tax evasion, and finally, high wages that were not supported by proportional productivity gains, all contributed to the decline in Greek economy's competitiveness. These issues reflect only a portion of the warning signs that should have warned of the impending financial crisis (Kindreich, 2017).

\subsection{The three Economic Adjustment Programs}

As a member of the Eurozone, the country was unable (at the onset of the crisis) to reduce interest rates or devalue its currency (to stimulate economic growth), and thus powerless in implementing its own monetary policy to match its fiscal and political needs. Unable to meet the massive financial burden from external borrowing, Greece applied for financial aid to the euro Member States and the International Monetary Fund (IMF). The country eventually received this support through its participation in three Economic Adjustment Programs which were designed in collaboration with the Commission, the European Central Bank (ECB) and the IMF. The financial assistance was intended to stabilize the national economic relative to its debt obligations and to prevent the crisis from spreading in the rest of the Euro area. The financial assistance provided with strict obligations for extensive structural reforms and austerity measures, which led to impoverishment, reduction of income and loss of property of the Greek citizens. The financial support provided by the first Economic Adjustment Program in 2010 was for $€ 110$ billion, whereas the other two financial Programs (one in 2012 and one in 2015) were for $€ 172.6$ billion and $€ 86$ billion, respectively (European Court of Auditors, 2017). According to the European Council of the European Union (2018), the third bailout program expired on August 20, 2018 and its aim was "to secure a return to sustainable economic growth in Greece". 


\subsection{The impact of the Greek financial crisis on European Union and "Grexit"}

The Greek economic crisis augmented the effects of the global financial crisis of 2008 that were felt throughout the European Union's financial infrastructure, with particular ramifications on the economies of Ireland, Portugal, and Cyprus (2010-2013). Spain and Italy also felt its consequences, though to a lesser degree. These countries were able to manage their financial challenges through negotiated financial support and the structural reforms of their national economic institutions and practices. Greece was less successful. This fact caused tension and discussions among the Eurozone countries, as to the wisdom of continuing to provide financial support (in the form of new loans) to an economy that was unable to meet its running obligations, on the condition of implementing austerity measures, which further shrink the national economy. There was disagreement on whether the country's exit from the Eurozone (known as "Grexit") would give policy-makers full control over the country's monetary policy, in order to respond to the crisis more effectively. Others argued that a Grexit would have devastating consequences on the economy and the Greek population. Questions also rose on the institutional framework under which the European Union operates (Nelson, Belkin and Jackson, 2017).

\section{THE GREEK FINANCIAL CRISIS FROM AN AUDITOR'S POINT OF VIEW}

\subsection{Effects of misreporting of economic performance and the lack of internal control}

Important contributors to Greek financial crisis have been the questionable accounting practices and the misreporting of economic performance by successive governments. These ultimately led to a loss of confidence that resulted in a significant increase of the interest rates on government and private debt. Moreover, the lack of effective oversight in many aspects of the public finances compounded the problems further.

In the report of the European Commission (2010) an in-depth analysis of the root causes of the public deficit of Greece is presented. The main findings of the report were the submission of incorrect data and non-respect of accounting rules and of the timing of the notification, the unreliability of data in the financial statements, the inappropriateness of the public accounting system for correct reporting, the lack of accountability and finally the unclear responsibilities of the national services which provided source data. The public financial management of Greece had a lack of transparency, compliance and reliability which are the key components of an effective internal control system which comprise a sound public financial management. Sarmas (2012) argues that "modern government must have control of public finance as the pilot has the control of its plane". The Greek government did not meet this condition, and therefore, lacked clarity relative to the exact percentage of the public deficit, which prevented it from assuming a proactive approach to the financial crisis and its disastrous consequences.

\subsection{The limited scope of the CoA's audit function relative to public expenditure}

The limited power of the CoA as prescribed by its legislative and structural framework, limited its external auditing scope to issues of legality and regularity, rather that economic and fiscal efficacy. Sarmas (2012) argues that "as no independent body was responsible in Greece for informing regularly the Parliament, the Government and the public on occasional or systemic cases of waste of money it was impossible to evaluate the proportion of useless spending included in the 36.150 billion euro public deficit of 2009 (15,4\%) GDP". It is worth noting that through the Third Review by the European Commission (2011), necessary measures have been suggested to the Greek government regarding specific areas of government expenditure, in order for the country to reach the deficit targets. 


\section{THE COURT OF AUDIT (CoA) OF THE HELLENIC REPUBLIC}

\subsection{Legal Framework of the $(\mathrm{CoA})$}

The CoA is one of the three Supreme Courts that operate in Greece, alongside the Supreme Civil and Criminal Court of Greece and the Council of State. The Court was created just after the independence of Greece in 1833 and is one of the oldest institutions of the modern Greek State. Its mandate was based on the French Cour des Comptes model (Wikipedia, 2018).

\subsection{Structure and responsibilities of the $\mathrm{CoA}$}

The CoA is a judicial Authority, which also has advisory (consultative) and auditing competences. All its jurisdictions are constitutionally defined. Specifically, "according to article 98 of the Constitution, the competence of the Court of Audit pertains mainly to auditing the expenditure of the State and Local Agencies, or other Entities subject to its audit by special laws, auditing contracts of large financial value made by the State or a Legal Entity equivalent to the State, auditing the accounts of public accounting officers and Local Government Agencies, providing an expert opinion upon laws on pensions, presenting to the Parliament a Report on the Annual Financial Statement and the Balance Sheet of the State and adjudicating on pension cases as well as cases related to the audit of public accounts and the liability of civil or military public servants" (CoA, 2018). The constitution, the competences and the organizational structure of the Court as well as the duties of its staff are defined in Law 4129 (2013). The main organizational elements of the CoA's system are composed of judicial officers and judicial employees. The first consists of judges that carry out their judicial duties by participating in the Plenary Session, the Judicial Sections and the Judicial Units of the Court. The second, consists of the administrative staff, which is organized in central and regional Commissioner's Offices in ministries, municipalities and prefectures of the State. This staff is responsible for carrying out the audits on behalf of the Court.

\subsection{The CoA as the unique external auditor of the Greek state}

It's worth noting that the most important responsibility of the Greek Judicial Authority is to carry out external audits of the financial statements and accounts of all public sector entities, a responsibility that was delegated to the Court in 2014 by the Law 4270. As stated in the Guide to Public Financial Management of USAID "external audits of public sector entities foster financial transparency and accountability and provide assurance to the government oversight bodies on operational integrity and financial reporting” (McClellan, McMorran, Kamenov, Wheeler, Malone, \& Saha, 2014).

\subsection{The audit categories of the CoA}

The constitutionally structured audit system of the Court consists of three distinct, equally concurrent and prudent forms of audit: (a) The audit of the Greek State's, the Local Government's and the Legal Entities' expenditure, (b) the preventive audit of high economic value public contracts prior to their signature, and (c) the ex-post audit of the accounts of the public accountants (13th General Meeting's Proceedings of the Plenary Session, 2016).

\subsubsection{Ex-ante audits}

The term "ex-ante" refers to audits that are carried out at the stage of budget implementation before the payment of the public expenditure and the completion of the complex administrative procedure for the disbursement of public funds. At this stage the regularity of the payment orders and the legality and regularity of the underlying public transactions are examined (Sarmas, 2012). Due to recent legislative reforms enacted by Law 4337 (2015), the ex-ante audits have been abandoned as a procedure for the expenses of the Greek State since 2017, while for the rest of the local Authorities the 
deadline for the ex-ante audit implementation is the end of 2018. The abolishment of the preventive audit caused significant changes in the way the CoA operates.

\subsubsection{Audits of high economic value public contracts prior to their signature}

During this type of auditing the CoA examines the legality of the draft high-value public contracts and decides whether the contract is to be signed or not depending on the audit findings (Sarmas, 2012).

\subsubsection{Ex-post audits}

The term "ex-post" refers to the audits that are usually carried out on a regular basis after the end of each financial year, in order to confirm the accuracy and the correctness of the account's recording, to ensure the regularity and legality of the public expenditure as well as to confirm that no public deficit exists in the public entities' financial accounts. Otherwise, in case of a deficit the public accountant is considered to be accountable by the Court. Sarmas (2012) holds that the deficits are usually incurred "simply by virtue of either an illegal or an irregular payment". According to Law 4129 (2013), at the ex-post stage of an audit implementation emphasis is also placed on the compliance with the basic principle of a sound financial management and to the economy, efficiency and effectiveness in the public transactions. Furthermore, the accuracy of the financial transactions and the financial operations of the public entities, the reliability of the internal control systems and the compliance of the public organizations with the previous recommendations made by the CoA are still examined (13th General Meeting's Proceedings of the Plenary Session, 2016). These audits are carried out in accordance with the International Auditing Standards of the International Organization of Supreme Audit Institutions (INTOSAI), of which the Greek Court is a member.

\subsubsection{Special financial and performance audits}

Special financial and performance audits are a new audit category that was introduced to the existing audit system of CoA by Laws 4055 (2012) and 4129 (2013) and is carried out in public sector entities, where the financial risk is estimated to be high. In relation to the performance audits, the scope of these audits is to ensure the efficacy of public spending. The CoA has developed and implements a documented audit manual that defines the framework for conducting these audits, which was officially approved in 2016 (13th General Meeting's Proceedings of the Plenary Session, 2016). It is worth mentioning that the efforts for the modernization of the audit procedures began in the year 2013 through a comprehensive cooperation among the CoA, the European Court of Auditors (ECA) and the Supreme Audit Institutions of Belgium, France and the Netherlands for a transfer of know-how.

\subsection{Current state of the CoA \& operational challenges}

The country's severe economic crisis and the large fiscal deficits highlighted the shortcomings and vulnerabilities of the traditional Greek public financial management systems and practices. The weaknesses that are associated with the mismanagement of public funds, the inadequate internal control systems, the lack of data integrity together with the inadequacy of the public accounting system relative to report accuracy, have compelled the CoA to challenge its overall strategic priorities and to adapt new audit methodologies and schemes that will reinforce its operational capabilities.

The audits that were presented earlier compose the interdependent subsystems that enable the CoA to successfully achieve its mandated mission. The conditions that contribute to this system's effectiveness relate to the audits completed on time (i.e. in the same financial year) (5th General Meeting's Proceedings of the Plenary Session, 2017). Embracing a risk-based thinking to audit execution and the abandonment of the ex-ante audits in the beginning of 2019 will increase the system's complexity, a fact that will necessitate new methods, systems and practices. 


\section{A SYSTEMS APPROACH TO THE AUDIT FIELDWORK OF COA}

\subsection{The CoA, dynamic complexity, \&a systems approach}

Public and private organizations operate on the complexities of an interconnected economic ecosystem that changes frequently due to social-cultural, legal, economic, political, environmental, ethical, demographic and technological forces. The Law of Requisite Variety formulated by Ross Ashby (1956) holds that in order for a system to remain stable, the number of states of its control function must be at least equal to (or exceed) the number of states of the system being controlled (Ashby, 1956). Ashby's law in this context implies that the rate of change that an organization must undergo, must equal the rate of change of the environment in which it operates, thus creating the conditions for homeostatic regulation (Varsos \&Assimakopoulos, 2016).

Systems thinking is the process of understanding how a set of elements affect one another within a defined unified whole. A systems approach focuses on the understanding of the interactions of the constituent elements of a unified whole that produce a behavior rather that the segregated parts of the system studied in isolation. In order to deliver long term results in the most effective and efficient manner possible, the organization must understand its key and enabling (support) processes, and how these processes fit together to produce an integrated whole that has the capacity to achieved its intended purpose. This typically means developing a capability to manage issues across teams and functions, with people throughout the organization having an understanding of the end-to-end process, not just their part of it (Assimakopoulos \& Varsos,2015).

The section that follows, makes use of the Design and Control Systemic Methodology (DCSYM) to explore the current structure of the $\mathrm{CoA}$ and the various forms of communication and control that reconcile aspects associated the organization's operations. The insight gained will be used to develop proposals relative to tools and standards that can be employed by management for the purpose of integrating a risk-based aspect into the organization's auditing function, which will enable the organization to integrate a proactive systems approach to the various processes associated with the auditing function's activities.

\subsection{Terminology, design, and coding forms used in the DCSYM}

The DCSYM is based on the principles of the problem structuring methodology (Panayotopoulos and Assimakopoulos, 1987). It draws on a set of simple rules, which produce semantic diagrams with a coherent mathematical description, which are capable of guiding multi-agent dialectic design processes concerning boundary critiques, structures, procedures and interventions (Assimakopoulos and Theoharopoulos, 2009). The DCSYM provides the practitioner with a practical means with which tomap-out complex structures, so as to illustrate both content and context. The semantic diagrams developed through the application of the methodology are extremely effective in illustrating system structures and problems which lack a clear problem definition (Assimakopoulos \& Varsos, 2015).

In the context of the DCSYM, a system is defined as a set of purposefully organized interdependent and interconnected elements that form a functional whole. An element is an individual or a subsystem, which is a single component of the whole. Systems and subsystems are schematically represented by a rectangle, while individuals are schematically represented by a circle. One or more elements may form a subsystem. Wholeness is generally an integral entity, say $\Omega$, which is associated with the combination of individuals and subsystems comprising the whole. Each system is represented by a mathematical entity $\Omega$, which is associated with the integrity of the subsystems and individuals of the system. In general, $\Omega=\mathrm{SUI}$, where $\mathrm{S}=\{\mathrm{s} 1, \mathrm{~s} 2, \ldots, \mathrm{sj}\}$ is the set of subsystems, and $\mathrm{I}=\mathrm{i} 1, \mathrm{i} 2, \ldots, \mathrm{ik}\}$ is the subset of the individuals. Each element of $\Omega$ has a unique positioning in the system, expressed as $\Theta$. This positioning is defined by a unique address of the form $[\mathrm{AS}]$ for a subsystem or (BI) for an 
individual. The statement $\Theta(\mathrm{s} 1)=[112 \mathrm{~S}]$ expresses that the element $\mathrm{s} 1$ is the second subsystem [112S] of the first subsystem [112S] which belongs to the first system [112S] (Assimakopoulos \& Varsos, 2015).

The control function within the DCSYM is defined as the purposeful action of a controller subsystem or individual, exercised on a controlled subsystem(s) or individuals(s). A control channel is always accompanied by a communication control channel, mainly at the opposite or occasionally with different direction. Communication and control channels are characterized as defined by Bowen (1981) in Table 1 (Assimakopoulos \& Varsos, 2015).

Table 1: Communication and control channels Source: Assimakopoulos \& Varsos (2015).

\begin{tabular}{|c|c|c|}
\hline Value & Value name & Nature of communication \\
\hline $\mathrm{P}, \mathrm{p}$ & Potential conflict & $\begin{array}{l}\text { Unconstructive communication in a conflict } \\
\text { situation }\end{array}$ \\
\hline $\mathrm{C}, \mathrm{c}$ & Communication & Positive communication \\
\hline $\mathrm{U}, \mathrm{u}$ & Purposeful action & Positive necessary communication \\
\hline $\mathrm{G}, \mathrm{g}$ & General interaction or influence & $\begin{array}{l}\text { Interaction with no particular stress on } \\
\text { communication }\end{array}$ \\
\hline $\mathrm{D}, \mathrm{d}$ & Distorted communication & $\begin{array}{l}\text { Incomplete communication with inevitable } \\
\text { distortion of information }\end{array}$ \\
\hline$\Delta, \delta$ & Distorted purposeful communication & $\begin{array}{l}\text { Incomplete necessary communication with } \\
\text { inevitable distortion of information conveyed }\end{array}$ \\
\hline
\end{tabular}

\subsection{The CoA, Viewed Through the DCSYM}

Using the DCSYM, it is possible to show in detail the structures and processes of the organization under review, the relationships and interactions between its structural elements (systems, subsystems and individuals) and the communication or control relationship between them (via the communication channels).

As can it be seen from the DCSYM diagram, the CoA consists of the Central Office (subsystem 1.1s) and the judicial employees (subsystems 1.2.s and 1.3.s), which carry out the ex-ante, the ex-post audits and the special financial and performance audits according to the Annual Audit Plan of CoA, prepared by the Planning Committee (subsystem 1.1.6s) and approved by the Plenary Session of the Court. The President of CoA (individual 1.1.1.1i) in cooperation with the Plenary Session of the Court (subsystem 1.1.1s), have the general decisive responsibility regarding public administration's audit issues. The planned audits are carried out by the auditors (subsystems 1.2.s and 1.3s), which are organized in audit teams in the Commissioner's Offices. In relation to the special financial and performance audits, they are chosen through the risk assessment of the financial data concerning the public entities deriving from the political and legal environment (subsystem 1E), the economic conditions (subsystem 2E) and public opinion (subsystem 3E). At the stage of audit implementation important is the role of the Audit Manual Committee (subsystem 1.1.2s) and the Steering Committee (subsystem 1.1.3s), two teams which support the auditors to achieve high audit quality in their audit work. Additionally, the Monitoring \& Supervision Committee of Audits (subsystem 1.1.7s) has the important responsibility of controlling and supervising the proper implementation of the special financial and performance audits. Finally, the CoA presents the financial audit report results and its recommendations to the Greek Parliament (5s subsystem), for the purpose of providing information relating to the financial status of the public entities. It should be noted, that the CoA as a member of INTOSAI (subsystem 3s), is continuously cooperating with the other Supreme Audit Institutions and with ECA (subsystem 2s), in 
an effort to adjust to the changes of the contemporary financial audits. Consequently, it is easy to assume that the Greek CoA is a complex dynamic changing system affected by its environment, a fact that requires constant adjustment to the any moment current circumstances. The current traditional structure of the CoA is not fully compatible with the new audit circumstances. A new organization process-oriented, risk-based structure tailored to the new audit methodologies would give the court the advantage of providing qualitative audit services.

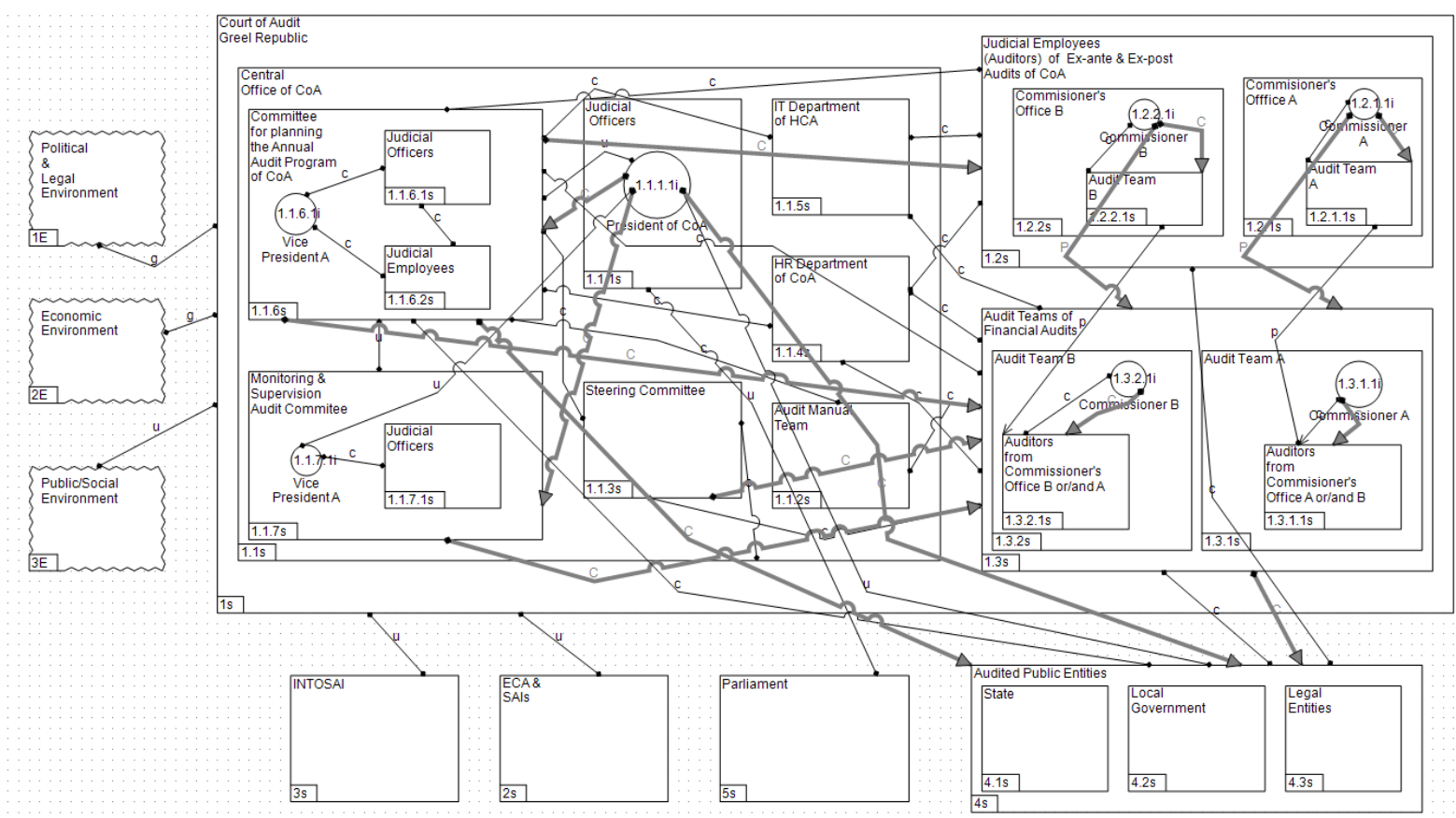

Figure 1. The CoA as viewed through the Design and Control Systemic Methodology (DCSYM)

\subsection{Application of international standards \& risk-based thinking for operational effectiveness}

Most guidelines and standards published by prominent International Standards Organizations respond to the complexity that is embedded in any organization's internal and external environments by embracing a process approach that relies on risk-based thinking. Ackoff (1971) defines a process as "a sequence of behavior that constitutes a system and has a goal-producing function". Simply stated, a process may be defined as an integrated set of interrelated activities that uses resources to transform inputs into outputs. The quality of the transformation activity is dependent on the relationship that hold among the process variables (people, equipment, input material or information, methods, and energy), which interact in a given environment for the purpose of producing a desired output. The operational capability (performance) of a process depends on the manner in which the process variables interrelate and the manner in which they operate. A system is said to exist when a number of interconnected processes interact in such a manner that their input-output relationships constitute the operational utility within the overall purpose of the whole. That is to say, the output of a single process (or a set of processes) forms the input (or inputs) for another process (or set of processes), within the boundary of the defined whole, affecting the overall performance of the whole and being affected by the whole. It is important to stress here that the system is not the sum of the processes of which it is comprised, but rather the product of their interactions (Assimakopoulos \& Varsos, 2015). Thus, through a process approach, a loose network of processes is turned into a coherent (integrated) system. A system of interrelated processes that is built on risk-based thinking within the context of a systems approach allows the organization to successfully apply systemic methodologies together with traditional 
management tools for the purpose of achieving a level of effectiveness through fact-based decision making, which in turn gives the organization awareness of the long term consequences of actions taken or avoided (Varsos \& Assimakopoulos, 2018).

Given the current level of complexity that is embedded in the CoA's operations (as illustrated through the DCSYM) the organization's management function will need to redefine the external and internal issues that are relevant to the organization's purpose and strategic direction, and augment its ability to achieve the intended result(s) of its stakeholders. For this purpose, a structured system will need to be developed through which management: (a) defines the systemic relations and interdependencies among the various subsystems (e.g., organizational functions, departments, functional teams, and the like) and the manner in which they interact so as to operate effectively as a structured functional whole (system); (b) identifies the information flows between these subsystems and recognizes their recurring patterns of behavior over time; (c) aligns its strategic priorities and tactical planning to the system's operational capabilities; and (d) develops and implements a monitoring and measurement scheme that will provide feedback relative to organization's overall performance requirements (objectives and goals).

The above can be accomplished through the implementation of a structured Quality Management System (QMS) that is designed consistent with the requirements of the ISO/IEC 17020:2012 international standard ${ }^{1}$, and ISSAI 40 and ISSAI $1220^{2}$. The QMS will serve as the organization's Internal Rules of Procedure, which will provide a coherent structure through which the CoA will control its key and enabling processes in a manner that assures conformance to legal and regulatory requirements and ensures the organization's uninterrupted capability to meet stakeholder expectations. Moreover, the QMS will provide a framework to the CoA to align its practices to both national and European benchmarks, and a systemic means through which to introduce corrective and/or preventive action in the event that stakeholder requirements are, for whatever reason, compromised. Moreover, the QMS will afford the CoA a coherent structure with which to: (a) demonstrate its impartiality and independence, (b) reinforce its structural requirements concerning its administrative and organizational and management processes, (c) provide adequate control of its resources (including personnel, facilities and equipment, and subcontractors), and (d) refine its audit activities (throughout their life-cycle), and standardize its complaint and appeals processes. Finally, the QMS will provide the structured mechanisms that will afford the CoA the operational agility to respond effectively to the complexity in its environment and to contribute to the economic and/or societal ecosystem of which it is an integral part. The section that follows makes use of a causal loop diagram to aid in visualizing how different variables in the proposed system are interrelated.

\subsection{The CoA Viewed Through System Dynamics}

System dynamics is a methodology and mathematical modelling technique developed by Jay Forrester of the MIT Sloan School of Management in the mid-1950s with the establishment of the MIT system dynamics group (Forrester, 1958, 1961). System dynamics has been successfully used to understand the dynamic behavior of complex systems. It uses information feedback and time delays that affect the behavior of a system as a means of evaluating business and other organizational and social contexts. A system dynamics approach places emphasis on structure and the processes within that structure which are responsible for the system's dynamic behavior. "Structure" within systems theory relates to the relationship between parts, elements, or variables within the system. These parts, elements or variables

\footnotetext{
1 The ISO/IEC 17020:2012 international standard is published by the International Organization of Standardization and specifies requirements for the competence of bodies performing inspection and for the impartiality and consistency of their inspection activities.

${ }^{2}$ ISSAI 40 is published by the International Organization of Supreme Audit Institutions and deals with Quality Control for SAIs (assists SAIs to establish and maintain a system of quality control which is appropriate to their mandate and circumstances), while ISSAI 1220 is practice Note provides supplementary guidance on ISA 220 - Quality Control for an Audit of Financial Statement.
} 
may be physical or abstract or both, depending on the nature of the system that dominates decisionmaking (Assimakopoulos \& Varsos, 2015). Through the use of system dynamics tools, the practitioner identifies circular chains of cause-and-effect relationships that are difficult to describe verbally, thus recreating the structure and dynamic processes in an effort to understand what is causing a particular pattern of behavior (Sterman, 2000).

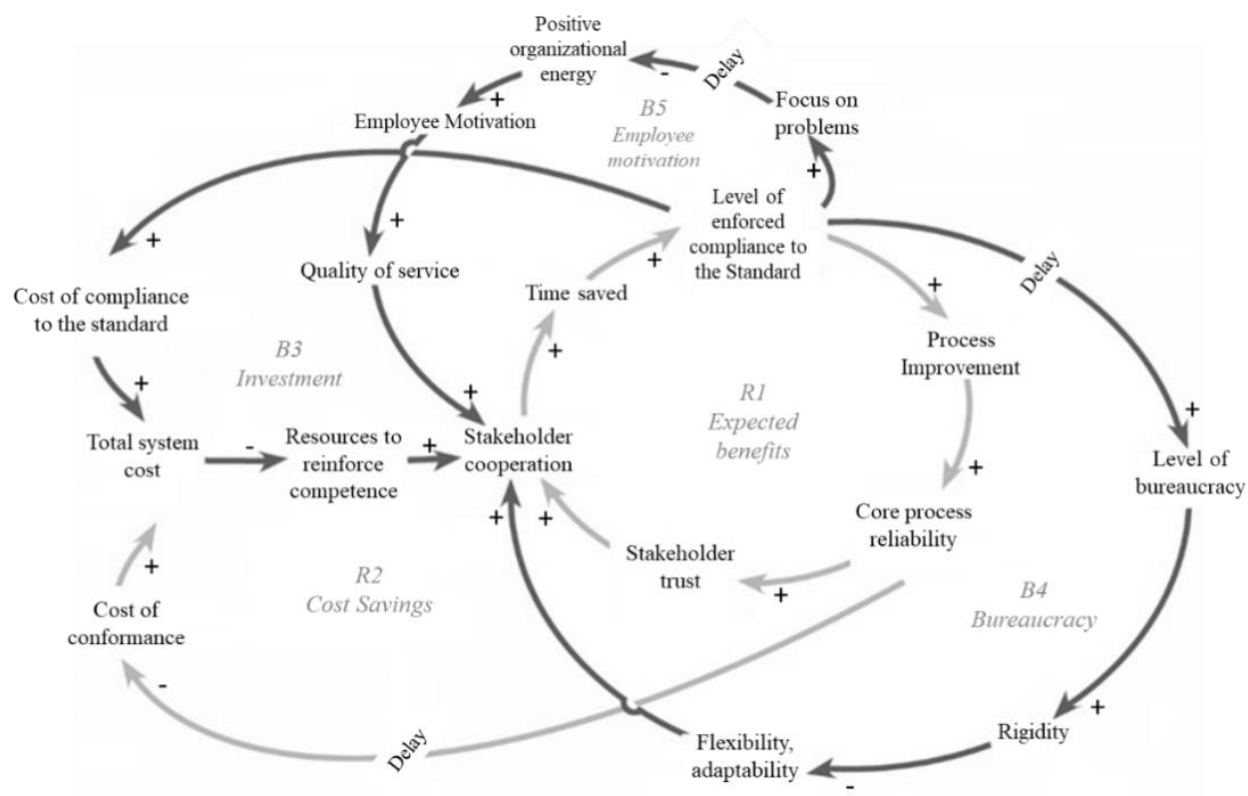

Figure 2: Causal Loop Diagram of expected results of implementing the QMS (Source: D. Grahn \& L. Keller Johnson (2018), adapted for an organization in the public sector)

As reflected in Figure 2, the positive reinforcing cycles of compliance to the international standards will improve stakeholder/supplier relationships. The negative impacts of increased costs of compliance (B2), the unavoidable rise in bureaucracy (B4), and a focus on problems brought about by employee motivation (B5) is balanced by the expected benefits, and the reinforced competence of the staff (R1 and R2).

\section{CONCLUSIONS}

Following the three consecutive Eurozone emergency loan programs, Greece is on the steep road to economic recovery. The massive debt that currently stands at above 180 percent of the country' GDP, however, will be a national liability for many years to come. Moreover, the structural problems that contributed to the crisis, remain for the most part unimpeded, making it harder for the country's economy to fully recover. The CoA can be instrumental in the nation's economic recovery and a key preventing measure to arrest financial mismanagement in the future. Thus, the need to continually challenge and expand the CoA's effectiveness within its current legal and regulatory framework has never been more important. In this context, the CoA needs to carry out its activities making use of innovative management practices and tools that reinforce its capacity to continually improve its key and enabling processes, and its ability to align its practices to both national and European benchmarks. The CoA's ability to respond effectively to the complexity in its environment is a key contributor to operational effectiveness and its net contribution to the economic ecosystem of which it is a part. In fact, the organization's capacity for change in a dynamic environment is an essential competency that must be imbedded in every aspect of its operations and an important prerequisite that is required to achieving sound results that meet the needs of both the organization and its stakeholders. The CoA's processes, culture and politics, employee required and emergent systems, existing and potential stakeholder needs are all essential elements of a unified system. The product of the interaction of these 
interdependent elements needs to be approached and understood as a unified whole. Understanding the fundamental systemic relationships which affect the behavior of the system over time will augment the CoA's capacity to manage the system's complexity.

\section{RÉFÉRENCES}

Ackoff, R.L. (1971). "Towards a system of systems concepts". Management Science, 17(11): 661671.

Ashby, R.W. (1956). An Introduction to Cybernetics. Chapman \& Hall, London.

Assimakopoulos, N.A. and Theoharopoulos, I.C. (2009). "The design and control systemic methodology (DCSYM): a multi-agent modelling and operation platform". Int. J. Applied Systemic Studies, 2(3): 193-217.

Assimakopoulos, N.A., \& Varsos, D.S. (2015). "A methodological systemic scheme using causal loops for the design and control of organizational change (DCSYM-2)". Int. J. Applied Systemic Studies, 6(1): 1-25.

Bowen, K. (1981). "A conflict approach to the modeling of problems of and in organizations", in Brans, J.P. (Ed.): Operational Research '8: 79-90, North-Holland, Amsterdam.

Court of Audit (Greece). (n.d.). In Wikipedia The free Encyclopedia. Retrieved September 25, 2018, from https://en.wikipedia.org/wiki/Court_of_Audit_(Greece).

European Commission, (2010). "Report on Greek Government deficit and dept. Statistics", Brussels. Retrieved September 25, 2018, from

https://ec.europa.eu/eurostat/documents/4187653/6404656/COM_2010_report_greek/c8523cfa-d3c14954-8ea1-64bb11e59b3a.

European Commission, (2011). "The Economic Adjustment Programme for Greece Third Review Winter 2011”. Directorate-General for Economic and Financial Affairs Publications, Brussels, Belgium. Retrieved September 25, 2018, from http://ec.europa.eu/economy_finance/publications/occasional_paper/2011/pdf/ocp77_en.pdf Forrester, J.W. (1958). "Industrial dynamics: a major breakthrough for decision makers". Harvard Business Review, July-August, 36(4): 37-66.

Forrester, J.W. (1961). Industrial Dynamics. Wright-Allen Press, Cambridge MA.

Grahn, D. \& Johnson, L.K. (n.d.). "Visibility Works: Implementing ISO/QS 9000”. In Systems Thinker. Retrieved September 28, 2018, from https://thesystemsthinker.com/visibility-worksimplementing-isoqs-9000/

Greece: The third economic adjustment programme. (n.d.). In The European Council. Retrieved September 25, 2018, from http://www.consilium.europa.eu/en/policies/financial-assistance-eurozonemembers/greece-programme/

Greek government-debt crisis. (n.d.). In Wikipedia The free Encyclopedia. Retrieved September 21, 2018, from https://en.wikipedia.org/wiki/Greek_government-debt_crisis\#Fraudulent_statistics Greek Republic Court of Audit. (n.d.). Retrieved September 25, 2018, from https://www.elsyn.gr/en International Organization of Supreme Audit Institutions (INTOSAI). (n.d.). Retrieved September 25, 2018, from http://www.intosai.org/about-us.html

Kindreich, A. (2017). “The Greek Financial Crisis (2009-2016)”. In CFA Institute. Retrieved September 21, 2018, from https://www.econcrises.org/2017/07/20/the-greek-financial-crisis-20092016/

Mclellan, H., McMorran, R., Kamenov, A., Wheeler, L., Malone, N. and Saha, R., (2014). "Guide to Public Financial Management". Deloitte Consulting LLP, United States Agency International Development (USAID). 
Nelson, R.M., Belkin, P. \&Jackson, J.K. (2017). “The Greek Debt Crisis: Overview and Implications for the United States". In Congressional Research Service. Retrieved September 25, 2018, from https://fas.org/sgp/crs/row/R44155.pdf

Panayotopoulos, A. and Assimakopoulos, N. (1987). "Problem structuring in hospitals". European J. Operational Research, 29(2): 135-143.

Proceedings of the Plenary Session (2016). 13th General Meeting of 27th June 2016. Court of Audit, Greece.

Proceedings of the Plenary Session (2017). 5th General Meeting of 29th March 2017. Court of Audit, Greece.

Sarmas, I. (2012). "The Greek Crisis and the Role of Audit". Ant.N. Sakkoulas Publishers, Athens, Greece.

Sterman, J.D. (2000). "Business Dynamics: Systems Thinking and Modeling for a Complex World”. Irwin McGraw-Hill, Boston, MA.

Upcoming special report on Greek financial crisis. (2017). In European Court Of Auditors. Retrieved September 25, 2018, https://www.eca.europa.eu/en/Pages/NewsItem.aspx?nid=9046

Varsos, D.S., \& Assimakopoulos, N.A. (2016). "A systems approach to alternative paradigms for organization and organizational change". Int. J. Applied Systemic Studies, 6(4): 302-326.

Varsos, D.S., \& Assimakopoulos, N.A. (2018). "Viability and change in the 21 st century organization: a cybernetic perspective". International Journal of Applied Systemic Studies, 8(2): 119-150. 